\title{
DISSECTING FACTORS RESPONSIBLE FOR INDIVIDUAL VARIATION IN PLANT FECUNDITY ${ }^{1}$
}

\author{
Carlos M. Herrera \\ Estación Biológica de Doñana, E-41013 Sevilla, Spain
}

\begin{abstract}
This paper analyses, on an individual plant basis, the various components determining seed production in the evergreen shrub Lavandula latifolia (Labiatae), in order to estimate their relative contributions to individual differences in fecundity. The relationships between fecundity and age, size, and growth rate are also examined. Experimental pollination and watering were done in an attempt to alter natural patterns of partial fecundity components. Fecundity of individual plants is partitioned into its absolute (number of inflorescences, number of flowers per inflorescence) and relative (fruits/flower and seeds/ fruit) partial components, and the following questions are addressed: (1) Are there individual differences in relative components of fecundity? (2) What are the proportional contributions of relative and absolute components of fecundity to individual variation in seed production? (3) Are relative measures of reproductive success reliable predictors of individual differences in fecundity? (4) When induced experimentally, do changes in partial fecundity components translate into modifications of the population's ranking of absolute fecundities?

Fecundity depended more on plant size than age, was unrelated to growth rate, and was limited by water, but not pollen, availability. Individual plants differed in all components of fecundity examined, and differences were consistent among years. The proportional contributions of the various components to individual differences in fecundity were very unequal. Almost all variation among plants in seed production $(\approx 90 \%$ of variance) was explained by the variances and covariances of number of inflorescences and number of flowers per inflorescence. Variation among plants in the two relative components (fruit and seed set), even though statistically significant, had a negligible influence on individual differences in fecundity. These patterns remained invariant despite significant modification of flower production and fruit set induced by artificially watering a part of the study population. Fruit and seed set alone are unreliable indicators of individual differences in the maternal component of fitness in L. latifolia, and a review of relevant literature indicates that this probably applies to other polycarpic plants as well. Plant reproductive biology studies may make erroneous inferences if they consider exclusively data on relative fruit and seed set, and neglect the absolute components of individual differences in fecundity. It is proposed that, to circumvent these potential problems, demographic aspects and absolute estimates of seed output on a per individual basis should be examined in addition to the customarily employed fruit and seed set measures.
\end{abstract}

Key words: fecundity components; flower production; fruit set; individual variation; Lavandula latifolia; Mediterranean scrublands; plant demography; reproductive biology; seed production; size hierarchy; water limitation.

\section{INTRODUCTION}

Recent studies on plant reproductive biology have often focused on the fitness consequences of intraspecific variation in pollination- or seed dispersal-related attributes. The consequences of variation in inflorescence size, flowering phenology, flower color and size, nectar production patterns, fruiting phenology, fruit size and structure, and infructescence size, among others, have been examined in many species, and inferences have often been drawn about the adaptedness of observed phenotypic patterns in these traits and about the likely evolutionary pathways leading to them (see

\footnotetext{
${ }^{1}$ Manuscript received 6 April 1990; revised 30 August 1990; accepted 25 September 1990; final version received 17 October 1990.
}

contributions in Bentley and Elias 1983, Jones and Little 1983, Real 1983, Estrada and Fleming 1986, Lovett Doust and Lovett Doust 1988, for reviews). Most frequently, the reproductive consequences of variation (either occurring naturally or induced experimentally) have been assessed in relative terms on a per flower, per inflorescence, per fruit, or per infructescence basis. Fruit set (proportion of flowers setting fruit), seed set (proportion of ovules setting seed), and fruit removal rate (proportion of a fruit crop that is successfully dispersed), for example, are some of the parameters used frequently when comparing the reproductive success associated with different character states of flowering- or fruiting-related plant attributes.

There is an essential conceptual difference between the relative success of a structure and the reproductive 
success of the individual bearing it. From an evolutionary viewpoint, it is the differences among individuals in reproductive success that is of interest. Several authors have warned about the potential biases inherent in the use of relative measures of reproductive success, instead of absolute figures expressed on a per individual basis (Wyatt 1980, Herrera 1982, 1988a, Zimmerman and Gross 1984, Andersson 1988; see also Primack and Kang 1989). If individual variation in rate-based estimates of reproductive success (describing the relative success of structures) is poorly correlated with individual variation in fecundity, then evolutionary inferences drawn from studies based on the former may be misleading or even erroneous. Plants producing large numbers of flowers often receive fewer pollinator visits, and have a lower fruit set, on a per flower basis than conspecifics producing fewer flowers, yet individuals with the largest floral displays are still those producing most seeds (Wyatt 1980, Andersson 1988, Klinkhamer et al. 1989). Similarly, in some bird-dispersed plants the proportion of seeds that is dispersed depends on traits like fruit size, crop size, and fruit seediness, yet absolute numbers are often unrelated to individual variation in these traits (Murray 1987, Herrera 1988a, Obeso 1989).

One of the reasons underlying the frequent contrast between the results of rate- and fecundity-oriented studies is probably that natural plant populations are characterized by broad variation in individual size, and this variation is closely paralleled by variation in potential (number of flowers) and realized (number of seeds) fecundity (Harper and White 1974, Harper 1977, Solbrig 1981, Solbrig and Solbrig 1984, Samson and Werk 1986, Weiner 1988) (throughout this paper, "fecundity" is used sensu Devlin and Stephenson 1987, i.e., the number of seeds produced via the female function). Broad differences among individuals in size and fecundity often exceed, and can offset, comparatively minor differences in relative measures of reproductive success (Herrera 1988a). Studies of plant demography and life history (mostly fecundity-oriented) and detailed analyses of plant reproductive systems (mostly rate-oriented) have tended to proceed independently (Willson 1983, Weller 1985), and a broad gap remains between them. For this reason, rate- and fecunditybased measures of reproductive success are rarely simultaneously available (but see, e.g., Davis 1981, Udovic 1981, Udovic and Aker 1981, Aker 1982, Schmitt 1983, Weller 1985), and even when they are it is difficult to assess the reliability of rate-based estimates of reproductive success as predictors of reproductive success at the individual plant level.

This paper analyses, on an individual plant basis, the various components determining seed production in Lavandula latifolia (Labiatae), in order to estimate their respective contributions to individual differences in fecundity. The dependence of fecundity on age, size, and growth rate is also examined. Experimental ma- nipulations of fecundity components are important in order to demonstrate, beyond inferences from observational data, to what degree individual differences in absolute fecundity actually are sensitive to modifications in their partial components. To this end, experimental pollinations and watering were done, in an attempt to alter natural patterns of partial fecundity components. Fecundity of individual plants is partitioned into two absolute (number of inflorescences, number of flowers produced by individual inflorescences) and two relative (proportional fruit and seed set) partial components. The total seed production of an individual in one reproductive season results from combining multiplicatively these four partial components, hence the relative contribution of each of them to individual variation in total seed production can be estimated. Specifically, the following questions are addressed: (1) Are there significant individual differences in relative (rate-based) partial components of fecundity (fruit and seed set)? (2) What are the proportional contributions of relative and absolute partial components of fecundity to individual variation in seed production? (3) Are rate-based estimates of reproductive success reliable predictors of individual differences in fecundity? (4) When experimentally induced, do changes in partial fecundity components translate into modifications of the population's ranking of absolute fecundities? I will show that, in $L$. latifolia, individual differences in fruit and seed set, even though significant, are practically unimportant in determining individual variation in seed production, and the ranking of fecundity is largely insensitive to experimentally induced alterations in some partial components. A review of pertinent literature indicates that the patterns documented here for L. latifolia most likely apply to other polycarpic plants as well.

\section{Plant Natural History}

Lavandula latifolia Med. is a low evergreen shrub (up to $35 \mathrm{~cm}$ high) producing long-stalked (up to 1.25 $\mathrm{m}$ high) inflorescences in early summer. It is a common species in the well-insolated undergrowth of mixed woodlands at middle elevations in the eastern and southeastern Iberian Peninsula. It reproduces exclusively by seed (C. M. Herrera, personal observation). Plants have a main taproot and a short (usually $<15$ $\mathrm{cm}$ ) main woody stem that is profusely and densely branched. Plants can be aged by counting growth rings on the woody stem.

The composition of the pollinator assemblage, the relation of the plant with pollinators, and aspects of its floral biology, have been described elsewhere (Herrera $1987 a, b, 1988 b, 1989,1990 a$ ). Flowers are hermaphroditic and protandrous, have pale-blue tubular corollas (tube length 7-8 $\mathrm{mm}$ ), and are produced over a short $(3-6 \mathrm{~cm})$ terminal portion of the stalks in a dichasium-like arrangement. Flowering lasts from early-mid July to late September-mid October (observa- 
tions in the period 1982-1989). Within single inflorescences, flowers open at a slow rate, and there are usually $<10$ flowers simultaneously open in each inflorescence. Flowering is largely synchronous on all inflorescences of the same plant. L. latifolia flowers are self-compatible, but spontaneous autogamy occurs very infrequently and seed set in the absence of pollinators is negligible. At the Sierra de Cazorla, where this study was conducted (see Study site and methods, below), the species is pollinated by a diverse (nearly 80 species) assemblage of bees, butterflies, and flies.

Flowers have four ovules, each potentially producing an independent nutlet. Developing nutlets (achenes) remain enclosed by the persistent calyx until maturation. For convenience, the unit formed by the persistent calyx plus the enclosed developing or ripe nutlet(s) will be termed here a "fruit." Nutlets develop synchronously within fruits, but fruit development is very asynchronous within plants and inflorescences, owing to the extended flowering period and slow rate of flower opening within single inflorescences. Fruit maturation takes nearly $5 \mathrm{wk}$ after anthesis, hence flowers and ripe seeds are simultaneously produced on single inflorescences over nearly two-thirds of the flowering period. Ripe nutlets ("seeds" hereafter) are small (mean \pm 1 $\mathrm{SD}=1.41 \pm 0.38 \mathrm{mg}, N=392$ ) and, after maturation, become loose within the calyx and fall independently to the ground.

\section{Study Site AND Methods}

This study was conducted during 1984-1989 in the Reserva de Navahondona-Guadahornillos, Sierra de Cazorla (Jaén province, southeastern Spain). The climate is of a Mediterranean type, with rainfall concentrated in autumn-winter (only $8.6 \%$ of total annual precipitation falls during June-September).

Most data on reproductive biology were obtained at a $L$. latifolia population growing around the intersection of Arroyo Aguaderillos and the track joining Roblehondo and Hoyos de Muñoz (1160 m elevation). This is the "Aguaderillos-1" site of Herrera (1988b), and the same denomination will be used here. Demographic and life history data were gathered from plants growing $300 \mathrm{~m}$ away from Aguaderillos-1 (the "Aguaderillos-2" site of Herrera 1988b). L. latifolia plants growing at the two sites must be considered as members of the same population, as there are no discontinuities between the two sites in the distribution of the species.

A permanent $200-\mathrm{m}^{2}$ plot was established in the Aguaderillos-2 site in August 1986, and all L. latifolia plants having $>10$ leaves (roughly $\geq 2 \mathrm{yr}$ in age) were permanently marked. Data on yearly inflorescence production by reproductive plants (those producing $\geq 1$ inflorescence in any of the study years) in the period 1985-1989 were used here to assess patterns of individual variation and annual consistency.

A sample of plants $(N=41)$ was collected in October 1984 in Aguaderillos-2, from an area contiguous ( $\leq 25$ m) with the site where the permanent plot was established $2 \mathrm{yr}$ later. The root system of these plants was excavated as far as the rocky substrate allowed, and the whole shrubs were collected. For each plant, the number of inflorescences produced in the preceding summer was counted (flowering stalks persist for months after the end of the flowering season), and all leaves were separated and weighed after drying to constant mass. Collected plants were aged by ring counting. This information was used to examine the relationship between inflorescence production, plant size (as estimated by dry mass of leaves), and age.

Individual variation in the absolute (inflorescence and flower production) and relative (fruit and seed set) components of fecundity was studied in Aguaderillos1 . There, 15 shrubs were individually marked in early July 1984 , and the number of inflorescences produced by each plant in each of six consecutive reproductive seasons (1984-1989) was counted. Three plants died before completing this study, and age at death was determined by ring counting. In October 1989, surviving plants were collected, and age and dry mass of leaves determined, using the same procedures described above for the Aguaderillos-2 collection. Furthermore, the distances between consecutive growth rings (yearly radial increments) on the woody stem were measured. As radial growth tended to be fairly symmetrical, a single set of measurements was taken per plant (along the longest radius of the stem's cross section). An ordered temporal sequence of lifetime annual radial increments was thus available for each Aguaderillos-1 marked plant.

Shortly after the start of the 1984 and 1986 flowering seasons, 10 inflorescences were selected at random on each marked plant, and individually marked with numbered tags. Flower, fruit, and seed production was followed over the whole flowering season in these inflorescences. A large proportion of the flowers that did not set fruit were shed within 2-3 wk of anthesis. Sixtytwo percent of the flowers on marked inflorescences that did not produce fruits $(N=5818$, both years combined) were abscised within $4 \mathrm{wk}$ of anthesis, and there were significant differences $(G=492.3, \mathrm{df}=14, P \ll$ .0001) among individual plants in the proportion of flowers that were shed following fruit failure (range 33.7-93.3\%). Moreover, counts of scars left by shed flowers were unreliable due to the dichasial structure of the inflorescence. For these reasons, accurate counts of flower production required close monitoring of inflorescences over the whole flowering period. Every 7$10 \mathrm{~d}$ from mid-July to mid-October in 1984 and 1986, all open and newly withered flowers on marked inflorescences were counted and color marked (using fastdrying marker pens) on the calyx, using different color codes for marking sessions on different dates. The cumulative number of marked flowers in an inflorescence over the whole flowering period represented its total flower production. A total of 8867 and 5839 flowers were marked on study plants in 1984 and 1986, re- 
spectively. The reduction in sample size in the $2 \mathrm{nd} \mathrm{yr}$ was due to lower flower production per inflorescence (see Results: Flower production by inflorescences, below) and the death of two of the marked plants.

Four weeks after each flower-marking session, all surviving color-coded calyces were counted and individually dissected without removing them from the plants. A longitudinal incision was made along the calyx using fine forceps, and the number of enclosed, nearly ripe seeds counted. I used this procedure because, due to the extended flowering period and asynchronous fruit development, extensive removal of earlier fruits for examination could modify the fruit and seed set of flowers opening later on the same inflorescence (Tamas et al. 1979, Stephenson 1981, Stephenson et al. 1988). On the other hand, had I waited until seeds were fully ripe (and thus physiologically decoupled from the parent plant, so that removal would not affect other developing fruits), shedding by the plant of an unknown number of seeds would have made estimates of actual seed production unreliable.

In 1984, the effect of additional pollen on fruit and seed production was investigated on 10 of the marked plants of the Aguaderillos-1 site, to examine possible pollinator limitation of seed production. On each of these plants, 10 experimental inflorescences were marked at the start of the flowering season in addition to those used for the study of flower and fruit production, which served as controls. Every 7-10 d over the whole flowering period, extra pollen taken from flowers on unmarked plants 10-25 m away was experimentally added to the stigmas of all open flowers on experimental inflorescences, using a fine brush. Pollen addition treatments were made to coincide in time with the marking sessions of open and withered flowers on control inflorescences. Pollen-treated flowers were color marked on the calyx, and seed and fruit set was determined using the same methods described directly above in this section for naturally pollinated inflorescences.

The influence of water availability on the fecundity of marked plants was investigated in 1986 at the Aguaderillos-1 site. Seven randomly chosen plants were artificially watered during most of the flowering season, and the remaining six individuals used as controls. Once per week, $25 \mathrm{~L}$ of water from a nearby stream were slowly poured over an area of $\approx 0.25 \mathrm{~m}^{2}$ around the base of the main stem of each treated shrub. The first watering was done on 7 July, and the last on 5 September.

Analyses of individual variation in flower production per inflorescence and fruit and seed set, have been conducted considering inflorescences as replicates representative of within-plant variation. Variation between individuals and years, and the effects of pollen and water addition, were tested using ANOVA. All analyses were performed with the GLM procedure in SAS, using Type III sum of squares due to the unbalanced nature of the data (SAS 1987). To improve nor- mality and reduce heteroscedasticity, original data were transformed for most analyses. Transformations used in each case are described at appropriate places in $R e$ sults. Throughout this paper, all means are reported $\pm 1 \mathrm{SD}$.

\section{RESULTS}

\section{Inflorescence production}

Aguaderillos-2 permanent plot.-Frequency distributions of the number of inflorescences produced per plant (NI hereafter) are shown in Fig. 1. The shape of the distributions remained remarkably constant among years, and there was no significant between-year heterogeneity in the relative distribution of reproductive plants among inflorescence number categories $(G=$ $22.56, \mathrm{df}=18, P=.21$ ). In all years, the distributions were leptokurtic and skewed to the right (skewness coefficient 1.78-2.03; kurtosis coefficient 3.77-5.94). The vast majority of plants $(>75 \%)$ produced $<40$ inflorescences, while a few individuals produced $>100$ inflorescences. Considering only those shrubs that flowered in the $4 \mathrm{yr}$, NI values for individual plants were positively correlated across years in the six possible pairwise combinations (Spearman rank correlation, $r_{s}$ range $=0.531-0.885, N=164, P \ll .0001$ in all cases). Over the four study seasons, therefore, there was significant consistency in the rank order of individuals with regard to their production of inflorescences.

The relative contributions of plant age and size (as estimated by total dry mass of leaves, DML hereafter) in explaining observed interindividual differences in inflorescence production, were examined using the sample of shrubs collected in 1984. In this sample, plant age ranged between 3 and $28 \mathrm{yr}$ (median $=12$ yr), DML between 0.41 and $34.95 \mathrm{~g}$ (median $=3.33$ $\mathrm{g})$, and number of inflorescences between 0 and 233

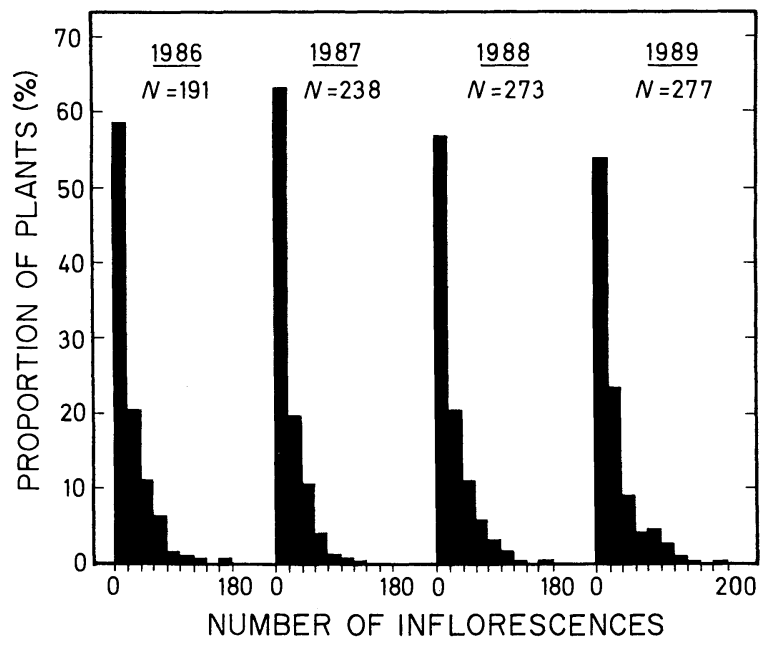

FIG. 1. Frequency distributions of the number of inflorescences produced by flowering Lavandula latifolia plants at the Aguaderillos-2 permanent plot, 1986-1989. $N=$ number of flowering shrubs occurring in the plot each year. 


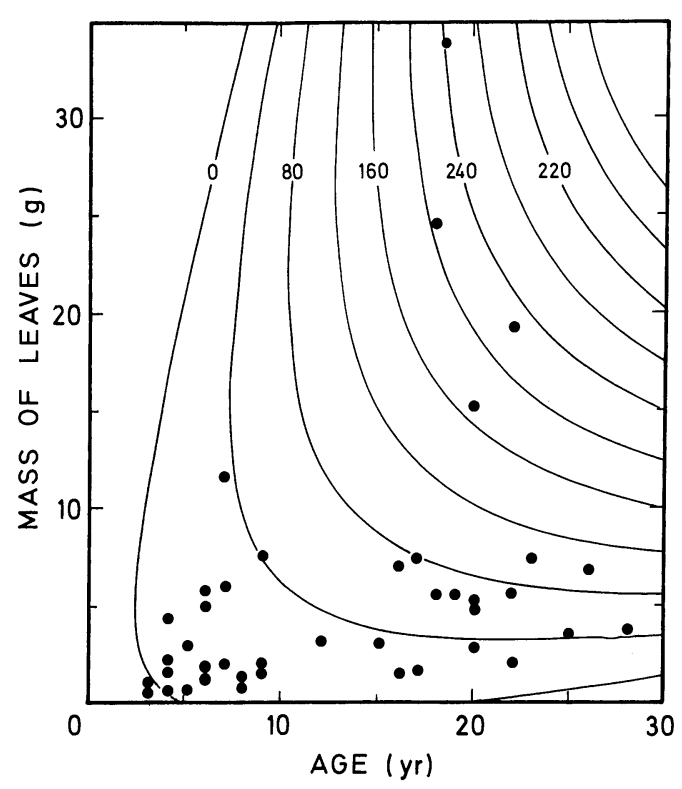

FIG. 2. Contour graph representing the fitted response surface of the number of inflorescences per plant $(Z)$ on plant age $(X)$ and total dry mass of leaves $(Y)$ in a sample of $L a$ vandula latifolia plants collected in autumn 1984 at the Aguaderillos-2 site (regression equation: $Z=-9.54+2.38 X$ $-0.10 X^{2}-0.20 Y-0.16 Y^{2}+0.69 X Y ; R^{2}=0.925$, see Table 2 for further details). Figures on isolines denote predicted values of the dependent variable (inflorescence number), and dots represent the position of sampled plants on the $X-Y$ plane.

(median $=33$ ). Quadratic regression was used to assess the relationship between the number of inflorescences produced by individual plants and their age and total dry mass of leaves. Three regressions were run, using plant age, DML, and both, as independent variables. Separate analyses were conducted for the whole sample and for reproductive individuals alone $(N=32)$. Results were similar, and those for the whole sample are reported here.

Inflorescence number increased linearly with plant age (the quadratic term in the regression was not significant), and nonlinearly with mass of leaves (Table 1). In the separate analyses, individual differences in DML explained a much greater proportion of the variance in number of inflorescences $(81.1 \%)$ than did plant age $(35.2 \%)$. Age and DML entered simultaneously explained only $11.4 \%$ more of the variance than DML alone (Table 1). The regression coefficients corresponding to the $\mathrm{DML}^{2}$ and $\mathrm{DML} \times$ age terms were the only statistically significant ones in this final regression. The fitted quadratic surface is represented in Fig. 2 for the age and DML ranges occurring in the sample.

Aguaderillos-1 plants. -I summarize in this section data on inflorescence production, in the period 19841989 , for the 15 marked plants used in the study of flower, fruit, and seed production (Table 2). While alive, all marked plants flowered every year.

In all years, plants differed broadly in the number of inflorescences produced (Table 2), with a range of from 153 (1987) to 429 (1989) inflorescences. Considering only those plants that remained alive over the 6-yr study period, the rank order of inflorescence production remained consistent between years. The 15 possible pairwise correlations between years were all positive and statistically significant $\left(r_{s}\right.$ range $=0.587-$ $0.944, N=12, P<.05$ in all cases).

No significant correlation was found in any of the six study years between NI and current plant age $(r$ range $=-0.220-0.272, N=12-15, P>.30$ in all cases). There was a significant positive correlation between NI produced in 1989 and DML at the time of collection that year $(r=0.698, N=12, P=.012)$. Quadratic regressions were not fitted due to the small sample size.

I attempted to relate individual variation in inflorescence production to differences in patterns of growth, using data on yearly radial increments of the woody stem. In none of the six years was inflorescence production significantly correlated with the current year's growth, the cumulative growth up to (and including)

TABLE 1. Summary of quadratic regressions of number of inflorescences produced by individual plants (dependent variable) against plant age (in years) and total dry mass of leaves (DML, in grams) (independent variables) in a sample of Lavandula latifolia plants $(N=41$; Aguaderillos-2 site, 1984).*

\begin{tabular}{cccccc}
\hline \hline $\begin{array}{c}\text { Independent variables } \\
\text { in equation }\end{array}$ & $\begin{array}{c}\text { Multiple } \\
R^{2}\end{array}$ & Term in regression & $\begin{array}{c}\text { Standard } \\
\text { regression } \\
\text { coefficient }\end{array}$ & $t$ value & $P$ \\
\hline Age & 0.352 & Age & 1.49 & 2.32 & .03 \\
& & Age $^{2}$ & -0.95 & 1.48 & .15 \\
DML & \multirow{2}{*}{0.811} & DML & 1.34 & 6.43 & $<.0001$ \\
& & DML $^{2}$ & -0.48 & 2.31 & .03 \\
Age and DML & \multirow{2}{*}{0.925} & Age & 0.29 & 1.21 & .23 \\
& & Age $^{2}$ & -0.36 & 1.48 & .15 \\
& & DML $^{2}$ & -0.02 & 0.09 & .93 \\
& & DML & -0.53 & 3.42 & .002 \\
\hline
\end{tabular}

* The three regressions are statistically significant $(F$ tests, $P<.001$ or better). 
TABLE 2. Inflorescence production, age, and growth (as assessed by yearly radial increments of the woody stem), of marked Lavandula latifolia plants, Aguaderillos-1 site.

\begin{tabular}{|c|c|c|c|c|c|c|c|c|c|c|c|}
\hline \multirow[b]{3}{*}{ Plant } & \multirow{2}{*}{\multicolumn{6}{|c|}{ Number of inflorescences }} & \multicolumn{5}{|c|}{ Measurements on collection (1989)* } \\
\hline & & & & & & & \multirow{2}{*}{$\begin{array}{l}\text { Age } \\
(\mathrm{yr})\end{array}$} & \multirow{2}{*}{$\begin{array}{c}\mathrm{DML} \\
(\mathrm{g})\end{array}$} & \multirow{2}{*}{$\begin{array}{l}\text { TRG } \\
(\mathrm{mm})\end{array}$} & \multirow{2}{*}{$\begin{array}{l}\text { MRG } \\
(\mathrm{mm})\end{array}$} & \multirow{2}{*}{$\begin{array}{c}\text { CVG } \\
(\%)\end{array}$} \\
\hline & 1984 & 1985 & 1986 & 1987 & 1988 & 1989 & & & & & \\
\hline A1 & 131 & 192 & 168 & 107 & 211 & 243 & 13 & 50.0 & 24.59 & 2.04 & 19.0 \\
\hline A2 & 43 & 54 & 54 & 42 & 25 & 41 & 15 & 30.0 & 9.53 & 0.68 & 67.3 \\
\hline A3 & 80 & 58 & 71 & 54 & 58 & 54 & 12 & 12.4 & 15.51 & 1.41 & 38.7 \\
\hline A4 & 89 & 92 & 101 & 97 & 138 & 62 & 20 & 21.1 & 11.37 & 0.59 & 61.3 \\
\hline A5 & 132 & 108 & 137 & 115 & 222 & 58 & 25 & 29.4 & 12.18 & 0.50 & 42.5 \\
\hline B1 & 220 & 150 & 183 & 195 & 415 & 458 & 14 & 42.9 & 12.37 & 0.95 & 27.1 \\
\hline B2 & 78 & 100 & 140 & 121 & 194 & 95 & 11 & 36.8 & 11.91 & 1.19 & 54.9 \\
\hline B3 & 50 & 44 & 26 & 47 & 34 & 29 & 10 & 3.2 & 8.21 & 0.91 & 38.2 \\
\hline B4 & 84 & 59 & 77 & 135 & 236 & 125 & 10 & 31.4 & 12.50 & 1.38 & 32.1 \\
\hline B5 & 88 & $-\dagger$ & - & - & - & - & $(13) \ddagger$ & - & - & - & - \\
\hline $\mathrm{Cl}$ & 107 & 119 & 139 & 162 & 307 & 210 & 16 & 19.2 & 21.80 & 1.45 & 22.6 \\
\hline $\mathrm{C} 2$ & 91 & 74 & 98 & 98 & 35 & $-\dagger$ & $(15) \ddagger$ & - & $(20.81) \S$ & $(1.60) \S$ & $(39.5) \S$ \\
\hline C3 & 106 & 92 & 105 & 109 & 110 & 98 & 15 & 19.4 & 16.08 & 1.14 & 39.4 \\
\hline $\mathrm{C} 4$ & 86 & 118 & 122 & 128 & 272 & 334 & 10 & 61.8 & 16.78 & 1.86 & 28.2 \\
\hline $\mathrm{C} 5$ & 51 & 20 & $-\dagger$ & - & - & - & $(14) \ddagger$ & - & - & - & - \\
\hline
\end{tabular}

* DML $=$ total dry mass of leaves; TRG = total radial increment of main stem over the plant's lifetime; MRG = mean annual radial increment of main stem over the plant's lifetime; CVG = coefficient of variation of yearly radial increments.

+ Plant died the preceding winter.

$¥$ Extrapolated from age at the time of death.

$\S$ Growth measurements up to the plant's death in the $1988-1989$ winter.

the current year, or the mean annual radial increment over the plant's lifetime (up to current year) (Table 3).

\section{Flower production by inflorescences}

Variation among individuals in the cumulative number of flowers produced by individual inflorescences over the whole flowering season (NFPI) was studied in 1984 and 1986 on the Aguaderillos-1 marked plants. Shortly after the start of the 1984 flowering season, harvester ants (Messor capitatus) removed most flower buds and open flowers from one plant, and it was excluded from the data set for that year. Two plants died between 1984 and 1986, and only 13 plants were available for study in 1986. A few inflorescences that were partly consumed by herbivorous mammals were excluded from the analyses. NFPI values were log transformed for the analyses.

There was considerable variation among inflorescence in flower production (range $=9-149$ flowers, all inflorescences, plants and years combined). In 1984, when no watering treatment was applied, there were broad and significant differences among plants in mean NFPI. Plant means ranged from $27.3 \pm 11.1$ flowers per inflorescence (plant A5, $N=10$ inflorescences) to $96.5 \pm 24.4$ flowers per inflorescence (plant C4, $N=$ 10 inflorescences) $(F=9.52, \mathrm{df}=13,124, P \ll .0001)$.

The effects of year and supplemental water on NFPI were tested simultaneously using ANOVA. The 1986 watering treatment was used to define two blocks of plants (Block 1, plants not watered in any year; Block 2 , those watered in 1986 but not in 1984). Two levels existed within each block, corresponding to these two study years. Within each block, individual plants were the same in the two years. Plants were nested within the year $\times$ block effect.

The block effect was not significant (Table 4A), indicating that inflorescences in the two subsamples of plants did not differ in flower production when the

TABLE 3. Product-moment correlation coefficients between the number of inflorescences produced each year by Lavandula latifolia individuals (Aguaderillos-1 site) and several variables related to the plant's previous growth (as assessed by yearly radial increments of the woody stem).*

\begin{tabular}{cccccccc}
\hline \hline & & \multicolumn{4}{c}{ Year } \\
\cline { 3 - 7 } Growth variable & & 1984 & 1985 & 1986 & 1987 & 1988 & 1989 \\
\hline Current year's radial increment & $r$ & 0.024 & 0.182 & 0.487 & 0.177 & 0.339 & 0.529 \\
& $P$ & NS & NS & 0.091 & NS & NS & 0.077 \\
Cumulative radial increment $\dagger$ & $r$ & 0.237 & 0.478 & 0.457 & 0.252 & 0.127 & 0.410 \\
& $P$ & NS & 0.099 & NS & NS & NS & NS \\
Mean annual radial increment $\dagger$ & $r$ & -0.011 & 0.323 & 0.238 & 0.160 & 0.136 & 0.457 \\
& $P$ & NS & NS & NS & NS & NS & NS \\
\hline
\end{tabular}

* Separate correlations were run for each of the six study years. For clarity, only $P$ values $<.10$ are shown (NS, $P \geq .10$ ). $N=12$ in 1989 , and $N=13$ in the other years.

$\dagger$ Computed using radial increments up to, and including, that of the current year. 
TABLE 4. ANOVA tables for the effects of year, plant, and block of plants, on flower production by individual inflorescences

(A), proportion of flowers maturing fruit in individual inflorescences (B), and number of seeds per fruit (C), in Lavandula latifolia (1984 and 1986, Aguaderillos-1 site). Plants were assigned to either of two blocks, depending on whether or not they received artificial watering in 1986. Original data were transformed for the analyses (see Results for transformations used in each case).

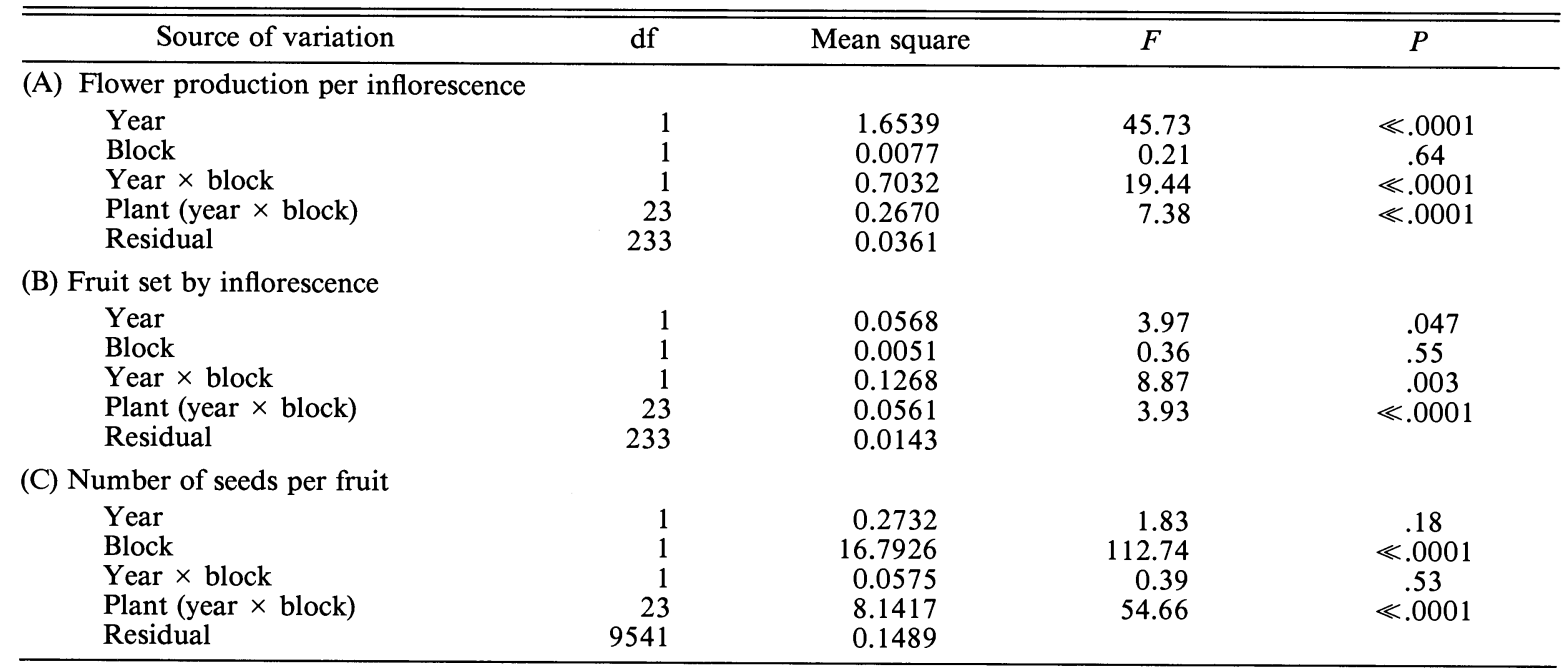

other effects were accounted for. The year effect was significant, indicating annual variation in flower production independent of the watering treatment. In Block 1 (untreated), mean NFPI declined from 1984 to 1986 (Fig. 3A). The plant effect was also significant, indicative of individual differences in flower production per inflorescence noted above. Finally, the block $\times$ year interaction effect, indicative of the watering treatment, was also significant. In Block 1, mean NFPI fell from 71.9 flowers in 1984 to 39.2 flowers in 1986. In Block 2 (watering in 1986), in contrast, mean NFPI varied from 60.1 in 1984 to 56.0 in 1986 (Fig. 3A). Among treated plants, therefore, supplemental water in 1986 was able to keep flower production by individual inflorescences at roughly the same levels as in 1984, while nontreated plants experienced that year a marked reduction in NFPI (Fig. 3A). In 1986, watered plants produced significantly more flowers per inflorescence than untreated ones $(F=9.59, P=.002$; ANOVA for 1986 data alone, plants nested within treatments) (Fig. $3 \mathrm{~A})$.

Despite the significant effect of watering on flower production by the inflorescences of treated plants in 1986, the rank order of plants remained essentially unchanged from 1984 to 1986 . For the whole set of plants, there was a significant rank correlation between years in the mean NFPI of individual plants $\left(r_{s}=0.734\right.$, $N=12, P=.006)$.

\section{Fruit set}

The proportion of flowers producing mature fruits was determined for each individually marked inflorescence from data of their cumulative flower and fruit production over the whole flowering season ( $=$ fruit set per inflorescence, FS hereafter). Unless otherwise stat- ed, the analyses reported in this section are based on data from the same years, plants, and inflorescences used above for the study of flower production by inflorescences. FS values were arcsine transformed for

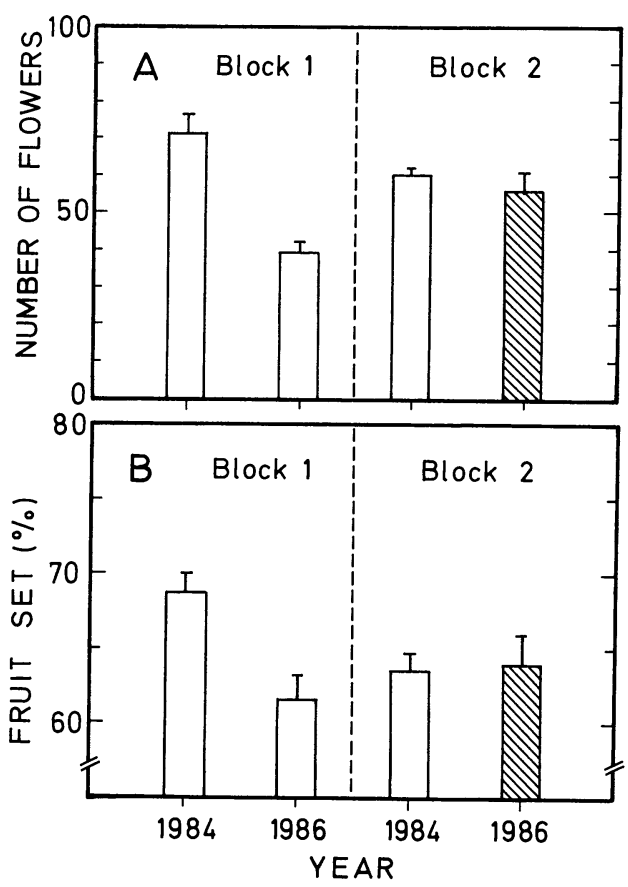

FIG. 3. Variation in mean flower production (A) and mean fruit set (percent of flowers maturing fruit) (B) of individual inflorescences, according to year and watering treatment (vertical bars extend over 1 SE of the mean). Shaded bars, data for experimentally watered plants in 1986. The two blocks of plants were defined by their assignments in the 1986 watering treatment and, within blocks, plants were the same in both years. See Table 4A, B for ANOVA results. 
all analyses, using a modification of the Freeman-Tukey transformation (Zar 1984: 240) to account for the occurrence of extreme FS values in inflorescences that produced few flowers.

For all plants, years, and inflorescences combined, FS ranged between 5.9 and $94.1 \%$. In 1984, when no watering treatment was applied, plant means ranged from $55.6 \pm 10.1 \%(N=9)$ to $76.9 \pm 9.2 \%(N=10)$, and differences between plants were statistically significant $(F=4.39$, df $=13,124, P \ll .0001)$.

Effect of watering. - The effects of year, plant, and supplemental water on FS were simultaneously tested using ANOVA (Table 4B). The model used was similar to that described in the preceding subsection, Flower production by inflorescences.

The block effect was not significant, revealing homogeneity of the two subsamples of plants in FS values when the other effects are accounted for. The year effect was significant, indicative of variation in fruit set between the two study seasons (Fig. 3B). The plant effect was highly significant, indicating differential fruit set among plants. The year $\times$ block effect, indicative of the watering treatment was significant. In Block 1 (untreated), mean FS declined from $68.7 \%$ in 1984 to $61.4 \%$ in 1986 . In Block 2 (watering in 1986), in contrast, mean FS remained virtually constant from 1984 $(63.5 \%)$ to $1986(64.0 \%)$ (Fig. 3B). Among treated plants, therefore, supplemental water in $1986 \mathrm{kept}$ fruit set at the same levels of 1984, while untreated plants experienced a reduction in fruit set with respect to 1984. In 1986, watered plants had a significantly higher fruit set than untreated ones $(F=3.71, P=.0002$; ANOVA for the 1986 data alone, plants nested within treatments) (Fig. 3B).

The rank order of plants with respect to mean FS in 1984 was uncorrelated with the order in $1986\left(r_{s}=\right.$ $0.224, N=12, P=.48)$. This may be due to the change in FS experienced the second year by treated plants as a consequence of supplemental water, but the possibility cannot be ruled out that FS was inconsistent among years, regardless of the watering treatment (the number of plants in Block 1 was too small for the correlation of 1984 and 1986 FS values to be reliable).

Effect of additional pollination. - Fruit set in experimental inflorescences was compared with that in untreated, open-pollinated ones from the same plants and over the same time period. On some dates, no open flowers were available for hand-pollination on the experimental inflorescences of a plant (mostly at the end of the flowering period). In these cases, data from control inflorescences for the same plants and dates were excluded from the analyses. The analyses are based on fruit set data from a total of 8086 flowers $(6176$ control, 1910 hand-pollinated).

The effects of plant and pollination treatment on FS were tested using a two-way ANOVA with interaction. There was a significant plant effect on FS $(F=3.83$, $\mathrm{df}=9,192, P=.0002)$, indicative of the heterogeneity among individuals in fruit set shown above for the whole set of marked plants. Neither the pollination treatment $(F=0.55, \mathrm{df}=1,192, P=.46)$ nor the plant $\times$ treatment interaction $(F=1.61, \mathrm{df}=9,192, P=$ .11) had a significant effect on the proportion of flowers setting fruit within individual inflorescences.

\section{Seed set}

Original data on number of seeds per fruit (NS) were transformed for the analyses using the Freeman-Tukey square root transformation (Zar 1984: 241). Analyses are based on data from the same years, plants, and individual inflorescences used earlier in the sections on flower production and fruit set.

The vast majority of fruits had either one or two seeds. For all plants, inflorescences, and years combined ( $N=9568$ fruits), the proportions of fruits bearing $1,2,3$, and 4 seeds were $58.6,36.7,4.5$, and $0.2 \%$, respectively (mean NS $=1.46 \pm 0.59$ seeds/fruit). There were significant differences among plants in mean NS in both study years (1984: $F=71.6, \mathrm{df}=13,5786, P$ $\ll .0001 ; 1986: F=45.2, \mathrm{df}=12,3755, P \ll .0001)$. Individual plant means varied between $1.15 \pm 0.25$ seeds/fruit (plant B5, $N=276$ fruits) and $1.87 \pm 0.73$ seeds/fruit (plant C2, $N=580$ fruits) in 1984, and between $1.19 \pm 0.39$ seeds/fruit (plant B2, $N=379$ fruits) and $2.07 \pm 0.82$ seeds/fruit (plant C2, $N=304$ fruits) in 1986. The rank order of individual plants with respect to mean NS was very consistent between years, as revealed by a nearly perfect rank correlation between mean NS values for individual plants in 1984 and $1986\left(r_{s}=0.930, N=12, P<.0001\right)$.

Supplemental water had no significant effect on the number of seeds per fruit of treated plants, as revealed by the nonsignificant effect of the block $\times$ year effect in ANOVA (Table 4C). The year effect was not significant. The block and plant effects were significant, revealing differences between and within groups of plants in mean NS.

The effect of supplemental pollen on the number of seeds set per fruit was examined by means of a twoway ANOVA, using the same data set used above in the analysis of fruit set. There was a strong plant effect on NS $(F=52.6, \mathrm{df}=9,5224, P \ll .0001)$, indicative of the significant heterogeneity among plants in fruit seediness noted above in this subsection. The pollination treatment had no effect on NS $(F=0.04, \mathrm{df}=$ $1,5224, P=.84)$.

\section{Total seed production}

The fecundity (total number of seeds, TNS) of individual plants was estimated for each reproductive season using the expression

$$
\mathrm{TNS}=\mathrm{NI} \times \mathrm{NFPI} \times \mathrm{FS} \times \mathrm{NS},
$$

where NI, NFPI, FS, and NS are the number of inflorescences, mean number of flowers produced per in- 
florescence, average proportion of flowers setting fruit, and mean number of seeds per fruit, respectively.

TNS estimates ranged between 2007 and 11000 seeds per plant in 1984, and between 682 and 11370 seeds per plant in 1986 . There was a significant rank correlation between years in total seed production by individual plants $\left(r_{s}=0.727, N=12, P=.007\right)$, revealing annual consistency in the relative fecundities of marked plants despite the significant positive effects of watering in 1986 on fruit set and flower production of the treated plants.

One way to determine the relative importance of partial components of fecundity in explaining individual variation in seed production, is to estimate the proportion of this variation that is attributable to individual differences in each of the partial measures. By definition, TNS estimates are completely determined by the values of the variables in the right side of Eq. 1 (independent variables), hence its variance is completely determined by their variances and covariances. Taking logarithms on both sides of Eq. 1, the variance of $\log$ (TNS) equals the sum of the variances of the logtransformed independent variables plus twice the sum of their covariances, hence additivity is achieved and partitioning may be performed (see Mott 1966 for further details and justification on this method). A potential shortcoming of the logarithmic transformation, however, is that it will tend to cause a distortion of the original scale of measurement, and the degree of distortion will depend on the absolute values of original variables (Mattson 1978). The rescaling effected by the transformation will tend to underestimate the variance contributions of variables with comparatively large values on the original measurement scale, such as, in this case, number of inflorescences and number of flowers per inflorescence.

There was no significant heterogeneity between the variance-covariance matrices of log-transformed independent variables in 1984 and 1986 . Homogeneity of the matrices was tested using Box's $M$ test (Cuadras 1981) (approximate $F=1.13$, df $=10,2945, P=.33$ ). Despite the significant influence of artificial watering on fruit set and flower production per inflorescence of treated plants, the structure of covariation among independent variables, and hence the pattern of relative variance contributions, remained essentially unchanged the second year. As the variance-covariance matrices did not differ significantly among years, data from the two years were combined to produce a pooled variance-covariance matrix, and variance of $\log$ (TNS) partitioned on this basis.

The relative contributions of the variances and covariances of log-transformed independent variables to the variation in $\log$ (TNS) was determined by dividing their variances and covariances (multiplied by 2) by the variance of $\log (\mathrm{TNS})$, and expressing the results as percentages (Table 5). Most individual variation in TNS was accounted for by variance in the number of inflo-
TABLE 5. Estimates of the proportion (expressed as percent) of individual variance in total seed production (TNS) contributed by variation in number of inflorescences (NI), mean number of flowers produced per inflorescence (NFPI), mean proportion of flowers setting fruit per inflorescence (FS), and mean number of seeds per fruit (NS). Values shown are the percent of total variance in $\log$ (TNS) contributed by the variances (values on the diagonal) and covariances (values off the diagonal) of independent variables.*

\begin{tabular}{lrrrr}
\hline & NI & NFPI & FS & NS \\
\hline \multicolumn{5}{c}{$\%$ of total variance in $\log ($ TNS) } \\
NI & 43.61 & & & \\
NFPI & 19.35 & 28.28 & & \\
FS & 2.47 & 4.48 & 2.66 & \\
NS & -6.88 & 1.22 & 0.32 & 4.49 \\
\hline
\end{tabular}

* As no significant heterogeneity was found between the matrices for the two study seasons, a pooled variance-covariance matrix was obtained for the $2 \mathrm{yr}$ combined (see Results: Total seed production for further details).

rescences and number of flowers produced per inflorescence, while the contribution of fruit set and number of seeds per fruit was negligible. The combined covariances of independent variables contributed comparatively little to TNS variance, indicating that neither negative nor positive interactions between partial measures of fecundity influenced significantly the variation in total number of seeds produced by individual plants. Furthermore, none of the correlations between independent variables (log-transformed) was statistically significant $(P>.10)$.

\section{DISCUSSION}

\section{Partial components and total seed production}

L. latifolia plants differed broadly in number of inflorescences produced, flower production by inflorescences, proportion of flowers setting fruit, and mean number of seeds per fruit. Inflorescence production was more closely related to plant size than to age, and it was unrelated to growth rate. Fruit set and flower production by inflorescences was limited by water availability. Summer water stress limits photosynthesis of mediterranean plants (Mooney 1983, Tenhunen et al. 1985), and it is not surprising that this effect translates into limitations of flower and fruit production (Lechowicz 1984). Neither fruit set nor seed set was affected by additional pollination. With the single exception of fruit set, the rank order of individual plants with respect to partial components of fecundity remained consistent between years.

The proportional contributions of the various partial components of fecundity to individual variation in seed production were very unequal. Almost all individual variation in seed production $(\approx 90 \%$ of variance) was explained by the variances and, to a lesser extent, the covariance of the two absolute partial components (NI and NFPI). Individual differences in the two relative components (FS and NS), even though statistically sig- 
nificant, had a negligible influence on individual variation in seed production. At this point, it is important to note that the logarithmic transformation, necessary to make variances additive, probably resulted in an underestimation of the variance contributions of absolute components, as these had comparatively larger values on the original measurement scale than relative ones. The pattern of relative variance contributions remained invariant among years, even though artificial watering in 1986 of about half the plants modified significantly their fruit set and flower production per inflorescence. This finding further strengthens the conclusion that relative measures of reproductive success are poor predictors of individual differences in fecundity in L. latifolia, and that the fecundity ranking in the population is largely insensitive to changes in the value of relative measures.

There are comparatively few studies partitioning individual fecundity into the components considered here, thus it is difficult to evaluate the generality of the patterns found for L. latifolia. These investigations, however, have consistently found that variation in total number of flowers produced is much more important than differences in seed or fruit set in determining the number of viable seeds produced in each reproductive episode by individual plants (Wyatt 1980, Udovic 1981, Winn and Werner 1987, Jordano 1988, 1989, Thompson and Pellmyr 1989). The generality of this phenomenon may also be assessed by examining separately the generality of each of the main reproductive and life history patterns that are responsible for it in the case of $L$. latifolia.

1) Individual variability in absolute partial components of fecundity (NI and NFPI) was greater than variability in relative partial components (FS and NS), as indicated by the comparative values of coefficients of variation (Table 6). This agrees with the prediction of greater individual variance in the parameters describing the earliest stages of the reproductive process, derived from the serial adjustment hypothesis of maternal investment during one reproductive episode proposed by Lloyd (1980). Similar patterns have been reported for a broad variety of species (Lloyd et al. 1980, Aker 1982, Winn and Werner 1987, Jordano 1989).

2) The role of covariances between partial fecundity components in explaining individual variance in fecundity was negligible. Most variance in fecundity was due to the variances of partial components. Negative covariances between fecundity components, reflecting trade-offs or complementarity between components, would reduce the contribution of variances. Both positive and negative correlations between fecundity components, generally involving flower production and fruit set, have been often reported (Wyatt 1980, Petersen et al. 1982, Montalvo and Ackerman 1987, Thompson and Pellmyr 1989). Even in those instances where significant complementarity occurs, trade-offs between
TABLE 6. Coefficients of variation (CV, \%) of total seed production (TNS) and partial components of fecundity among individuals of $L$. latifolia in the two study years. $\mathrm{NI}=$ number of inflorescences; NFPI = mean number of flowers produced per inflorescence; $F S=$ mean proportion of flowers setting fruit; NS = mean number of seeds per fruit. $N=14$ plants in 1984 , and 13 plants in 1986 .

\begin{tabular}{ccccrc}
\hline \hline Year & TNS & NI & NFPI & FS & NS \\
\hline 1984 & 52.2 & 45.0 & 35.3 & 9.3 & 16.4 \\
1986 & 62.8 & 41.2 & 39.1 & 13.7 & 15.5 \\
\hline
\end{tabular}

absolute and relative partial fecundity components are comparatively unimportant in reducing the overwhelming influence of the variances of absolute components on individual differences in fecundity (Wyatt 1980, Andersson 1988, and present study).

3) The distribution of flower production per plant in the population was asymmetrical, positively skewed, with comparatively few individuals producing a disproportionate number of flowers. There is a vast literature on size hierarchies in plants showing that this is the commonest situation in natural plant populations (see reviews in Solbrig and Solbrig 1984, Weiner and Thomas 1986, Weiner 1988), and that size hierarchies ordinarily translate into fecundity hierarchies (Salisbury 1942, Solbrig 1981, Cook and Lyons 1983, Solbrig and Solbrig 1984, Scheiner 1987).

4) Individual variation in flower production per plant closely paralleled variation in plant size, and was only weakly related to age differences and unrelated to radial growth patterns. Despite the assertion of Waller (1988) that "... the association between plant size and fecundity ... needs to be tested far more often than it has been so far," this relation seems to hold universally among plants (Harper and White 1974, Harper 1977, Inouye et al. 1980, Gross 1981, Kawano et al. 1982, 1986, Kawano and Miyake 1983, Abbott 1985, Augspurger 1985, Garwood and Horvitz 1985, Silvertown 1985, Ohara and Kawano 1986, Samson and Werk 1986, Jordano 1988, Ohlson 1988, Solbrig et al. 1988, among others).

In summary, then, all the reproductive and life history elements contributing to the negligible importance of relative components in explaining individual variation in fecundity in L. latifolia commonly occurs in other plants, further pointing to the generality of the results reported here.

\section{Short-term vs. lifetime fecundity}

At the study area, maximum longevity recorded for L. latifolia is $32 \mathrm{yr}$, although most plants are senescent and produce few, if any, flowers after age 25 . The first reproduction generally takes place at ages between 5 and $10 \mathrm{yr}$ (C. M. Herrera, personal observation). The present study thus encompasses only a fraction of the $\approx 15$-yr average reproductive life-span for an individual of the species, and observed individual differences in fecundity may not reliably describe individual dif- 
ferences in lifetime fecundity. It has been proposed that comparatively fecund (on a short-term basis) individuals in plant populations may incur reduced future survival, growth, or fecundity as a consequence of the "cost of reproduction" (Law 1979). Should this happen in L. latifolia, patterns of differential fecundity documented here would not accurately reflect actual differences between plants in lifetime fecundity.

If exceptionally fecund individuals incur greater reproductive costs than those producing fewer seeds, one would expect that the ranking of individuals in the population with respect to fecundity would be inconsistent among successive reproductive episodes, and/ or that more fecund individuals actually die younger than less fecund ones. In $L$. latifolia, the ranking of surviving individuals with respect to inflorescence production (the main determinant of seed production) remained remarkably constant over 4-yr (Aguaderillos2) and 6-yr (Aguaderillos-1) periods. Long-term demographic data are not still available for $L$. latifolia. The limited data from Aguaderillos-1 (Table 2), however, do not suggest that the most fecund individuals (e.g., plants B1, A1, C4) live any less long that the least fecund ones (e.g., A2, B3, C5). In fact, the three plants that died in the course of the study had yearly fecundities below the median for the population while they were alive, and actually lived for fewer years than the most fecund plants would have, had I not collected them (Table 2). Annual constancy in fecundity rankings is apparently the rule in populations of polycarpic plants (Solbrig 1981, Sork 1983, Vander Kloet and Cabilio 1984, Zimmerman 1984, Linhart and Mitton 1985, Weller 1985, Herrera 1988a, McCarthy and Quinn 1989). On the other hand, in the few polycarpic perennials where lifetime fecundity has been examined, the most fecund individuals on a yearly basis not only did not have a shorter life-span, but actually tended to live longer than the less fecund ones (Solbrig 1981, Cook and Lyons 1983, Bullock 1989). Observations on $L$. latifolia are thus representative of other polycarpic plants, further suggesting that fecundity rankings obtained over several reproductive episodes may be reasonably accurate predictors of individual differences in lifetime fecundity.

This implies that a cost of reproduction, in terms of reduced survival or future reproduction, is not universal among polycarpic plants. A negative association between current reproductive effort and future growth or reproduction has been suggested for some species (Piñero et al. 1982, Montalvo and Ackerman 1987, Clark and Clark 1988, Inghe and Tamm 1988, Ackerman 1989, Snow and Whigham 1989, Zimmerman and Aide 1989), but no relation has been found in others (Willson 1986, Hutchings 1987, Keeler 1987, Reekie and Bazzaz 1987, Horvitz and Schemske 1988, Inghe and Tamm 1988). Horvitz and Schemske (1988), after reviewing the evidence available up to that date, concluded that more experimental data are needed to demonstrate unambiguously the existence of a demographic cost of reproduction.

\section{ConClusion}

Even though individual $L$. latifolia plants differ significantly in fruit and seed set, differences in these relative measures are poor predictors of individual variation in absolute seed production. Furthermore, the evidence available suggests that observed patterns of differential fecundity among individuals most likely mirror differential lifetime fecundity. A review of the literature illustrates that $L$. latifolia is not unique in any of the aspects considered here, and that similar patterns occur frequently in other plants. It may thus be concluded that, in many species, fruit and seed set alone are unreliable indicators of individual differences in the maternal component of fitness. These two measures have been traditionally used to assess intraspecific variation in maternal reproductive success in studies of plant reproductive biology. Insofar as the results presented here apply to other species as well, evolutionary inferences drawn from studies of maternal reproductive success that are based on rate-based measures may be seriously flawed.

The "rates-versus-numbers" problem illustrated in this paper is not unique to the study of the maternal component of reproduction, but presumably applies also to some other fields in plant reproductive ecology where rate-based, relative measures have been frequently used (e.g., seed dispersal, seed predation; De Steven 1981, 1983, Murray 1987, Herrera 1988a). In order to circumvent this potential problem, estimates of reproductive success based on the absolute seed output of individual plants (e.g., Herrera 1990b), and demographic aspects (Travis and Henrich 1986), should be considered instead of, or in addition to, routinely used measures of reproductive success describing the relative success of reproductive structures (seeds, fruits, flowers).

\section{ACKNOWLedgments}

I am most grateful to Manolo Carrión and my wife, Dori, for their enthusiastic help with the field work, which was essential for the completion of this study. The Instituto para la Conservación de la Naturaleza and the Agencia de Medio Ambiente authorized by work in the Sierra de Cazorla and provided invaluable housing facilities there. During the final preparation of this paper, I was supported by grant PB870452 from the Dirección General de Investigación Científica y Técnica, Ministerio de Educación y Ciencia.

\section{Literature Cited}

Abbott, I. 1985. Reproductive ecology of Banksia grandis (Proteaceae). New Phytologist 99:129-148.

Ackerman, J. D. 1989. Limitations to sexual reproduction in Encyclia krugii (Orchidaceae). Systematic Botany 14: 101-109.

Aker, C. 1982. Regulation of flower, fruit and seed production by a monocarpic perennial, Yucca whipplei. Journal of Ecology 70:357-372. 
Andersson, S. 1988. Size-dependent pollination efficiency in Anchusa officinalis (Boraginaceae): causes and consequences. Oecologia (Berlin) 76:125-130.

Augspurger, C. K. 1985 . Demography and life history variation of Puya dasylirioides, a long-lived rosette in tropical subalpine bogs. Oikos 45:341-352.

Bentley, B., and T. Elias, editors. 1983. The biology of nectaries. Columbia University Press, New York, New York, USA.

Bullock, S. H. 1989. Life history and seed dispersal of the short-lived chaparral shrub Dendromecon rigida (Papaveraceae). American Journal of Botany 76:1506-1517.

Clark, D. B., and D. A. Clark. 1988. Leaf production and the cost of reproduction in the Neotropical rain forest cycad, Zamia skinneri. Journal of Ecology 76:1153-1163.

Cook, R. E., and E. E. Lyons. 1983. The biology of Viola fimbriatula in a natural disturbance. Ecology 64:654-660.

Cuadras, C. M. 1981. Métodos de análisis multivariante. Editorial Universitaria, Barcelona, Spain.

Davis, M. A. 1981. The effect of pollinators, predators, and energy constraints on the floral ecology and evolution of Trillium erectum. Oecologia (Berlin) 48:400-406.

De Steven, D. 1981. Predispersal seed predation in a tropical shrub (Mabea occidentalis, Euphorbiaceae). Biotropica 13: 146-150.

-1983. Reproductive consequences of insect seed predation in Hamamelis virginiana. Ecology 64:89-98.

Devlin, B., and A. G. Stephenson. 1987. Sexual variations among plants of a perfect-flowered species. American Naturalist 130:199-218.

Estrada, A., and T. H. Fleming, editors. 1986. Frugivores and seed dispersal. Dr. W. Junk, Dordrecht, The Netherlands.

Garwood, N. C., and C. C. Horvitz. 1985. Factors limiting fruit and seed production of a temperate shrub, Staphylea trifolia L. (Staphyleaceae). American Journal of Botany 72: 453-466.

Gross, K. L. 1981. Predictions of fate from rosette size in four "biennial" plant species: Verbascum thapsus, Oenothera biennis, Daucus carota, and Tragopogon dubius. Oecologia (Berlin) 48:209-213.

Harper, J. L. 1977. Population biology of plants. Academic Press, London, England.

Harper, J. L., and J. White. 1974. The demography of plants. Annual Review of Ecology and Systematics 5:419-463.

Herrera, C. M. 1982. Breeding systems and dispersal-related maternal reproductive effort of southern Spanish bird-dispersed plants. Evolution 36:1299-1314.

1987a. Components of pollinator "quality": comparative analysis of a diverse insect assemblage. Oikos 50: 79-90.

- 1987b. Componentes del flujo génico en Lavandula latifolia Medicus: polinización y dispersión de semillas. Anales del Jardín Botánico de Madrid 44:49-61.

- 1988a. The fruiting ecology of Osyris quadripartita: individual variation and evolutionary potential. Ecology 69:233-249.

- $1988 \mathrm{~b}$. Variation in mutualisms: the spatio-temporal mosaic of a pollinator assemblage. Biological Journal of the Linnean Society 35:95-125.

- 1989. Pollinator abundance, morphology, and flower visitation rate: analysis of the "quantity" component in a plant-pollinator system. Oecologia (Berlin) 80:241-248.

- 1990a. Daily patterns of pollinator activity, differential pollinating effectiveness, and floral resource availability, in a summer-flowering mediterranean shrub. Oikos 58:277-288.

- $1990 \mathrm{~b}$. The adaptedness of the floral phenotype in a relict endemic, hawkmoth-pollinated violet. 1. Reproductive correlates of floral variation. Biological Journal of the Linnean Society 40:263-274.
Horvitz, C. C., and D. W. Schemske. 1988. Demographic cost of reproduction in a neotropical herb: an experimental field study. Ecology 69:1741-1745.

Hutchings, M. J. 1987. The population biology of the early spider orchid, Ophrys sphegodes Mill. II. Temporal patterns in behaviour. Journal of Ecology 75:729-742.

Inghe, O., and C. O. Tamm. 1988. Survival and flowering of perennial herbs. V. Patterns of flowering. Oikos 51:203219.

Inouye, R. S., G. S. Byers, and J. H. Brown. 1980. Effects of predation and competition on survivorship, fecundity, and community structure of desert annuals. Ecology 61: $1344-1351$.

Jones, C. E., and R. J. Little, editors. 1983. Handbook of experimental pollination biology. Van Nostrand Reinhold, New York, New York, USA.

Jordano, P. 1988. Polinización y variabilidad de la producción de semillas en Pistacia lentiscus L. (Anacardiaceae). Anales del Jardín Botánico de Madrid 45:213-231.

- 1989. Pre-dispersal biology of Pistacia lentiscus (Anacardiaceae): cumulative effects on seed removal by birds. Oikos 55:375-386.

Kawano, S., A. Hiratsuka, and K. Hayashi. 1982. Life history characteristics and survivorship of Erythronium japonicum. Oikos 38:129-149.

Kawano, S., and S. Miyake. 1983. The productive and reproductive biology of flowering plants. X. Reproductive energy allocation and propagule output of five congeners of the genus Setaria (Gramineae). Oecologia (Berlin) 57:613.

Kawano, S., M. Ohara, and F. H. Utech. 1986. Life history studies on the genus Trillium (Liliaceae). II. Reproductive biology and survivorship of four eastern North American species. Plant Species Biology 1:47-58.

Keeler, K. H. 1987. Survivorship and fecundity of the polycarpic perennial Mentzelia nuda (Loasaceae) in Nebraska sandhills prairie. American Journal of Botany 74:785-791.

Klinkhamer, P. G. L., T. J. de Jong, and G. J. de Bruyn. 1989. Plant size and pollinator visitation in Cynoglossum officinale. Oikos 54:201-204.

Law, R. 1979. The cost of reproduction in annual meadow grass. American Naturalist 113:3-16.

Lechowicz, M. J. 1984. The effects of individual variation in physiological and morphological traits on the reproductive capacity of the common cocklebur, Xanthium strumarium L. Evolution 38:833-844.

Linhart, Y. B., and J. B. Mitton. 1985. Relationships among reproduction, growth rates, and protein heterozygosity in ponderosa pine. American Journal of Botany 72:181-184.

Lloyd, D. G. 1980. Sexual strategies in plants. I. An hypothesis of serial adjustment of maternal investment during one reproductive session. New Phytologist 86:69-79.

Lloyd, D. G., C. J. Webb, and R. B. Primack. 1980. Sexual strategies in plants. II. Data on the temporal regulation of maternal investment. New Phytologist 86:81-92.

Lovett Doust, J. L., and L. L. Lovett Doust, editors. 1988. Plant reproductive ecology: patterns and strategies. Oxford University Press, New York, New York, USA.

Mattson, W. J. 1978. The role of insects in the dynamics of cone production of red pine. Oecologia (Berlin) 33:327349.

McCarthy, B. C., and J. A. Quinn. 1989. Within- and amongtree variation in flower and fruit production in two species of Carya (Juglandaceae). American Journal of Botany 76: 1015-1023.

Montalvo, A. M., and J. D. Ackerman. 1987. Limitations to fruit production in Ionopsis utricularioides (Orchidaceae). Biotropica 19:24-31.

Mooney, H. A. 1983. Carbon-gaining capacity and allocation patterns of mediterranean-climate plants. Pages 103119 in F. J. Kruger, D. T. Mitchell, and J. U. M. Jarvis, 
editors. Mediterranean-type ecosystems. Ecological Studies, Analysis and Synthesis $\mathbf{4 3}$.

Mott, D. G. 1966. The analysis of determination in population systems. Pages 179-194 in K. E. Watt, editor. Systems analysis in ecology. Academic Press, New York, New York, USA.

Murray, K. G. 1987. Selection for optimal fruit-crop size in bird-dispersed plants. American Naturalist 129:18-31.

Obeso, J. R. 1989. Fruit removal and potential seed dispersal in a southern Spanish population of Berberis vulgaris subsp. australis (Berberidaceae). Acta Oecologica, Oecologia Plantarum 10:321-328.

Ohara, M., and S. Kawano. 1986. Life history studies on the genus Trillium (Liliaceae). I. Reproductive biology of four Japanese species. Plant Species Biology 1:35-45.

Ohlson, M. 1988. Size-dependent reproductive effort in three populations of Saxifraga hirculus in Sweden. Journal of Ecology 76:1007-1016.

Petersen, C., J. H. Brown, and A. Kodric-Brown. 1982. An experimental study of floral display and fruit set in Chilopsis linearis (Bignoniaceae). Oecologia (Berlin) 55:7-11.

Piñero, D., J. Sarukhán, and P. Alberdi. 1982. The costs of reproduction in a tropical palm, Astrocaryum mexicanum. Journal of Ecology 70:473-481.

Primack, R. B., and H. Kang. 1989. Measuring fitness and natural selection in wild plant populations. Annual Review of Ecology and Systematics 20:367-396.

Real, L., editor. 1983. Pollination biology. Academic Press, Orlando, Florida, USA.

Reekie, E. G., and F. A. Bazzaz. 1987. Reproductive effort in plants. 3. Effect of reproduction on vegetative activity. American Naturalist 129:907-919.

Salisbury, E. J. 1942. The reproductive capacity of plants. Bell and Sons, London, England.

Samson, D. A., and K. S. Werk. 1986. Size-dependent effects in the analysis of reproductive effort in plants. American Naturalist 127:667-680.

SAS. 1987. SAS/STAT guide for personal computers. Version 6 edition. SAS Institute, Cary, North Carolina, USA.

Scheiner, S. M. 1987. Size and fecundity hierarchies in an herbaceous perennial. Oecologia (Berlin) 74:128-132.

Schmitt, J. 1983. Individual flowering phenology, plant size, and reproductive success in Linanthus androsaceus, a California annual. Oecologia (Berlin) 59:135-140.

Silvertown, J. 1985. Survival, fecundity and growth of wild cucumber, Echinocystis lobata. Journal of Ecology 73:841849.

Snow, A. A., and D. F. Whigham. 1989. Costs of flower and fruit production in Tipularia discolor (Orchidaceae). Ecology 70:1286-1293.

Solbrig, O. T. 1981. Studies on the population biology of the genus Viola. II. The effect of plant size on fitness in Viola sororia. Evolution 35:1080-1093.

Solbrig, O. T., W. F. Curtis, D. T. Kincaid, and S. J. Newell. 1988. Studies on the population biology of the genus Viola. VI. The demography of $V$. fimbriatula and $V$. lanceolata. Journal of Ecology 76:301-319.

Solbrig, O. T., and D. J. Solbrig. 1984. Size inequalities and fitness in plant populations. Oxford Surveys in Evolutionary Biology 1:141-159.

Sork, V. L. 1983. Mast-fruiting in hickories and availability of nuts. American Midland Naturalist 109:81-88.

Stephenson, A. G. 1981. Flower and fruit abortion: proximate causes and ultimate consequences. Annual Review of Ecology and Systematics 12:253-279.

Stephenson, A. G., B. Devlin, and J. B. Horton. 1988. The effects of seed number and prior fruit dominance on the pattern of fruit production in Cucurbita pepo (zucchini squash). Annals of Botany 62:653-661.

Tamas, I. A., D. H. Wallace, P. M. Ludford, and J. L. Ozbun. 1979. Effect of older fruits on abortion and abscisic acid concentration of younger fruits in Phaseolus vulgaris L. Plant Physiology 64:620-622.

Tenhunen, J. D., O. L. Lange, P. C. Harley, W. Beyschlag, and A. Meyer. 1985. Limitations due to water stress on leaf net photosynthesis of Quercus coccifera in the Portuguese evergreeen scrub. Oecologia (Berlin) 67:23-30.

Thompson, J. N., and O. Pellmyr. 1989. Origins of variance in seed number and mass: interaction of sex expression and herbivory in Lomatium salmoniflorum. Oecologia (Berlin) 79:395-402.

Travis, J., and S. Henrich. 1986. Some problems in estimating the intensity of selection through fertility differences in natural and experimental populations. Evolution 40:786790.

Udovic, D. 1981. Determinants of fruit set in Yucca whipplei: reproductive expenditure vs. pollinator availability. Oecologia (Berlin) 48:389-399.

Udovic, D., and C. Aker. 1981. Fruit abortion and the regulation of fruit number in Yucca whipplei. Oecologia (Berlin) 49:245-248.

Vander Kloet, S. P., and P. Cabilio. 1984. Annual variation in seed production in a population of Vaccinium corymbosum L. Bulletin of the Torrey Botanical Club 111:483488.

Waller, D. M. 1988. Plant morphology and reproduction. Pages 203-227 in J. L. Lovett Doust and L. L. Lovett Doust, editors. Plant reproductive ecology: patterns and strategies. Oxford University Press, New York, New York, USA.

Weiner, J. 1988. The influence of competition on plant reproduction. Pages 228-245 in J. L. Lovett Doust and L. L. Lovett Doust, editors. Plant reproductive ecology: patterns and strategies. Oxford University Press, New York, New York, USA.

Weiner, J., and S. C. Thomas. 1986. Size variability and competition in plant monocultures. Oikos 47:211-222.

Weller, S. G. 1985. The life history of Lithospermum caroliniense, a long-lived herbaceous sand dune species. Ecological Monographs 55:49-67.

Willson, M. F. 1983. Plant reproductive ecology. John Wiley \& Sons, New York, New York, USA.

- 1986. On the costs of reproduction in plants: Acer negundo. American Midland Naturalist 115:204-207.

Winn, A. A., and P. A. Werner. 1987. Regulation of seed yield within and among populations of Prunella vulgaris. Ecology 68:1224-1233.

Wyatt, R. 1980. The reproductive biology of Asclepias tuberosa. I. Flower number, arrangement, and fruit-set. New Phytologist 85:119-131.

Zar, J. H. 1984. Biostatistical analysis. Second edition. Prentice-Hall, Englewood Cliffs, New Jersey, USA.

Zimmerman, J. K., and T. M. Aide. 1989. Patterns of fruit production in a Neotropical orchid: pollinator vs. resource limitation. American Journal of Botany 76:67-73.

Zimmerman, M. 1984. Reproduction in Polemonium: a five year study of seed production and implications for competition for pollinator service. Oikos 42:225-228.

Zimmerman, M., and R. S. Gross. 1984. The relationship between flowering phenology and seed set in an herbaceous perennial plant, Polemonium foliosissimum Gray. American Midland Naturalist 111:185-191. 